\title{
Your Phone Has Internet - Why Are You at a Library PC? Re-imagining Public Access in the Mobile Internet Era
}

\author{
Jonathan Donner $^{1}$ and Marion Walton ${ }^{2}$ \\ ${ }^{1}$ Microsoft Research India, Lavelle Rd, Bangalore, India 500080 \\ ${ }^{2}$ The Centre for Film and Media Studies, University of Cape Town, Upper Campus, \\ Arts Block, Cape Town \\ jdonner@microsoft.com, marion.walton@uct.ac.za
}

\begin{abstract}
This study focuses on teenage users of public internet access venues (PAVs) in low-income neighborhoods of Cape Town. It documents their cultivation of detailed ICT repertoires to make the most of available ICTs. It highlights the continuing importance of PAVs as supplements for poorly equipped schools and reveals the incompleteness of any supposed transition to mobile-only internet use. While the mobile internet is opening up opportunities for young people, its current form still conflicts with the easy (global) rhetoric of a closing digital divide and the end of the PAV. We recommend policy and design actions (effecting rules, training, messaging, functionality, and $\mathrm{Wi}-\mathrm{Fi}$ ) to reconfigure PAVs to be more useful "in the age of the mobile internet". Though some actions require support from policymakers, this is fruitful ground for designers and technologists. We identify steps that can be undertaken immediately, rather than waiting for future device convergence or lower tariffs.
\end{abstract}

Keywords: Libraries, ICT4D, Shared Access, South Africa, Developing Regions, Human Factors, Mobile Phones.

\section{Introduction}

This paper revolves around a question: "If you have the internet in your pocket, why do you still visit a public access venue?" Mobile Internet access is growing worldwide, propelled by lower cost smart phones and data enabled "feature phones" costing as little as USD\$50. Though mobile handsets may not provide the same functionality as a PC, the mobile internet promises to bring a billion or more people online [1].

The arrival of this private, accessible, but perhaps not optimal mobile internet has implications for 'traditional' public access venues (PAVs), such as libraries, telecenters and cybercafés serving low-resource communities. We suggest that recent assertions in the practitioner literature (e.g., [2,3]) about the irrelevance of public access in the age of the mobile deserve further scrutiny. Only a handful of studies have systematically addressed the interplay amongst these forms of access [4-6], and no one has examined the effect of mobile internet use on particular groups engaging in specific activities or the strategic choices made by users confronted with a potential repertoire $[7,8]$ of access choices. This paper describes a study in Cape Town, South Africa, 
emphasizing an ongoing role for public access venues even among some mobile internet users, and suggesting ways to redesign and reconfigure public access venues to be more useful in the era of the mobile internet.

This study focuses on older teenage PAV users in low-income neighborhoods of Cape Town, identifying the roles of PAV and mobile phones in their educational, cultural, civic, and health-related involvement. The consequences of PAV use are important for young people who confront various information-related challenges associated with transitions between school, tertiary studies, and a forbidding job market where only one in eight adults under 25 years of age find formal employment.

The mixed-design deployed four activities: (1) Semi-structured initial interviews with operators of 36 PAVs in the Western Cape Province; (2) Detailed interviews, activity/drawing probes, and task analyses with 53 teenage PAV users in 6 sites, including neighborhood libraries, larger 'central' libraries, and some cybercafés; (3) a closed-end questionnaire administered to 280 PAV users in Cape Town, and (4) an extensive debriefing session with leaders of three PAV organizations in Cape Town.

The results of the three main activities are detailed in [9], prepared as part of a broader multi-country study on public access to computing. This paper condenses the report [9], and adds the results of the consultation to find:

1. Teenage users have developed practices which help them negotiate the respective strengths and weaknesses of public access and private mobiles.

2. The PAV ecology supports a valued and non-substitutable repertoire of practices for resource-constrained users, even those with 'the internet in their pocket'.

3. Teens can use a combination of mobile and public access internet resources to participate in media production (though not all of them do so).

4. PAV operator policies influence the chances for simultaneous, complementary use of the mobile internet in the venue.

We discuss specific implications for design and policy, implementable in the short term, to increase the utility of PAVs in the mobile age. In essence, the PAV can 'welcome the mobile' into the venue through rule changes (to allow file transfers), staff training, $\mathrm{Wi}-\mathrm{Fi}$, and spatial reconfiguration to support sociality and play.

\section{The South African Context}

South Africa remains a society with extreme differences between rich and poor [10]. Its distinctive patterns of ICT use $[11,12]$ make it an important case in policy initiatives around digital inclusion [13]. Hardware is expensive due to import duties and lack of domestic manufacturing. Cell coverage is good but data, whether via terrestrial DSL or wireless GPRS/3G connections, remains relatively expensive. DSL lines are frequently capped with monthly limits as low as 1GB. Wireless data is purchased by bundles (similar to prepay airtime minutes), encouraging careful attention to a "running meter" [14]. Public access [15] to the internet in South Africa is available in libraries, NGO-run telecenters, schools, and cybercafés [16, 17]. 
By 2010, South Africa had over 100\% mobile penetration (50 million subscriptions) but only 743,000 fixed broadband subscribers [18]. Market research suggests that 9 million unique users subscribe to the GPRS data channel [19]. Meanwhile MXit, a Java-based GPRS "internet-lite" chat application, has become popular enough, as a first-time mobile internet experience, to spawn moral panics, new phrases, and political sagas [20-24]. Thus "mobile centric" [25] internet use is increasingly prevalent, particularly in urban areas and among youth [26, 27]. Germane to our study population, most grade-11 teens in low-income township schools in Cape Town used their mobiles to access the internet as early as 2008 [28].

Books, libraries, and computers are scarce in most South African schools [29]. Unequal access to good teaching and facilities testify to contemporary class inequalities and to racial discrimination in past provisioned under apartheid [30]. Since 2002/3, public schools in the Western Cape Province, where Cape Town is located, have benefited from a rollout of computer labs and at around the same time, the SmartCape project began providing internet access to libraries in disadvantaged areas of Cape Town. With simply not enough PCs or internet access points at school or at home, teens turn to libraries, cybercafés, and other PAVs to augment their access. We had no difficulty finding teens in Cape Town libraries every afternoon and on weekends, waiting for their allotted periods of free internet access on the SmartCape computers.

The participants in this study have been growing up in post-democracy in an era of dramatic social change. Opportunities increased for Black households, just as growing unemployment plunged many into poverty. Unemployment is particularly serious for young people who leave school facing national unemployment rates of $25 \%$ [31].

If young people are unsuccessful in their exams or cannot afford to study further, contacts in their social networks may be their major source of opportunities for employment or income. Ideally, they need to find a way to develop interests or networks that connect them with the worlds of work and higher education. Many are skilled users of the ICT and their practices suggest a continuing role of PAVs in supplementing for poorly equipped schools, highlighting shortcomings of the mobile internet as currently experienced.

\section{Framing/Perspective}

The literature on the roles of mobiles in the theory and practice of "Information and Communication Technologies for Development" (ICT4D) is too voluminous [32] to cover here. Our interest is not voice calls or even text messaging but mobile internet use in relation to shared PC and internet access. We do not presume that mobile internet use is a substitute for public access or that it is irrelevant to those who use PAVs. Indeed, it may often not be the same "internet" on the mobile, as access modes range from accessing WAP sites to running enclosed applications, such as a chat clients, to downloading premium content or games from operator websites [33].

We join other recent HCI papers to explore communicative ecologies and repertoires in resource constrained settings [34, 35]. Communicative ecologies involve interactions among technologies, sociality, and discourse [36, 37]. Information or 
cultural ecologies are characterized by 'hybrid' interactions of physical and digital [8, 38]. We adopt ecological metaphors to explain the roles of mobile internet, other ICTs, social networks, and PAV spaces in the repertoires of young people. This approach allows us to acknowledge young people's agency and supplement it with an awareness of power, first, the long, powerful shadows cast by institutionalized schooling centered around adult institutional authority and second, the overall contours of participation, as sculpted and truncated by economic forces.

\section{Methods}

Our project was intended to explore the leading edge of a non-equally-distributed phenomenon (complementary use of mobile internet and PAVs). The theoretical target population was urban teens from historically disadvantaged populations in South Africa who lack access to resources. Due to cost constraints, we pursued nonrepresentative, purposive sampling during all phases of data gathering. Our sample is urban, restricted to Cape Town. Our informants were all PAV users. Thus our results are exploratory in nature, and should be interpreted to identify patterns and issues relevant to design and to policy, rather than to fix specific estimates of behavioral frequencies in the broader population. All questionnaires and recruiting procedures were prepared in accordance with the University of Cape Town regulations for research with human subjects, including written parental consent for participants under the age of 18 .

In phase one, we conducted semi-structured qualitative phone or in-person interviews with 36 PAV operators in the Western Cape (11 cybercafés, 5 telecenters/NGO facilities, and 21 libraries). We selected sites at random from a list of Cape Town libraries located in low-resource neighborhoods and included the city's two central libraries. Telecenters and Cybercafés were selected using a convenience sampling method, focused on the same low-resource neighborhoods in Cape Town.

The interviews were the same in the phone and face-to-face conditions. The questions were formulated to consider the use mobile internet. Interviews were conducted in the language of the respondents (English, isiXhosa, or Afrikaans). These brief 1520 minute interviews were recorded, transcribed, translated, and then entered into Excel for analysis. Face-to-face interviewees were provided a prepay airtime voucher worth 40 Rand (\$4.48) as an honorarium.

In phase two, we recruited 53 teenage participants from public access venues around Cape Town, primarily the public libraries in Delft (14\%) and Langa (14\%), Cape Town's Central Library (13\%), and the African Axess Internet Cafe in Langa (11\%). Selected venues provide insight into a mix of government and commercial operators in diverse neighborhoods. We interviewed both Afrikaans and isiXhosa speaking participants (who were mostly multi-lingual). The group included 24 young women (45\%) and 29 young men (55\%) who ranged in age from 13 to 19 years old, with an average age of 17 years.

The interaction with participants varied depending on availability of PCs, safety of bringing a mobile to the venue, time, and the evolving needs of the project. 
An interaction consisted of some or all of the following components. (a) A semistructured interview on PAV and mobile internet behaviors inquired about the task that had led the participant to come to the venue. (b) Assisted drawing of a project network diagram detailed the socio-technical resources (including PCs and mobiles) recruited for the participant's most recent school project [39]. Finally, (c) a videotaped facilitated task analysis on a PC or mobile using the "think aloud" method [40]. Participants received a R15 (\$1.68) airtime honorarium.

In phase three, we distributed a questionnaire that focused on validating and quantifying issues and patterns found in earlier phases. We used leave-behind or selfadministered questionnaires, with a R10 (\$1.12) incentive for completing the 15 minute task. The questionnaire was available in English-only, Afrikaans + English, and isiXhosa + English versions.

In June and July 2011, we distributed questionnaires at seven PAVs. Overall, 294 users, 171 users at 4 libraries and 141 users at 3 cybercafés (missing value on venue=3), responded to the survey. Overall, $67 \%$ of respondents were male and $33 \%$ were female. Respondents ranged in age from 12 to 55 years of age. The highest completed education among the adults ranged from high school and "matric" (passed final high school exams) up through some university training.

The questionnaire captured a diverse set of Cape Town residents, not strictly the poorest of the urban poor. Overall, $56 \%$ of respondents spoke isiXhosa as their first language, followed by English (27\%), Afrikaans (24\%), and Zulu (1\%). English was listed as a second language by $52 \%$ of respondents. Furthermore, $62 \%$ of respondents said they were unemployed, $17 \%$ were employed, $10 \%$ were part-time employees, and $8 \%$ were self-employed. Concerning their living arrangements, $92 \%$ had electricity in their homes and $81 \%$ of respondents could get to the PAV in 20 min. or less.

Finally, in phase four, we held a three-hour workshop to discuss findings with representatives of African Access (a cybercafé chain), The Cape Town Libraries SmartCape initiative, and the manager of the Cape Access project of the Provincial Government of the Western Cape. During the workshop, we tested and refined initial findings and developed recommendations with these key stakeholders.

\section{$5 \quad$ Findings}

\subsection{Teenage Users Have Developed Practices Which Help Them to Negotiate the Respective Strengths and Weaknesses of Public Access and Private Mobiles}

In this section, we describe how teens navigate the interrelated affordances and constraints made available via mobiles and PAVs. Free use (as in a library) supports more resource-intensive goals (requiring storage space, time, and bandwidth) and stable media production. Paid use (such as a phone) supports time-sensitive goals, interpersonal communication, and low bandwidth media use.

In phase three, we asked the respondents about locations, beyond the shared access venue, where they could get Internet access. Figure 1 shows that nearly half of respondents had access at home. In our target group of teens, $42 \%$ of survey respondents had home access to a PC while $30 \%$ of in-depth interviewees owned a PC. These 
estimates are higher than national averages but are consistent with independent estimates for urban areas ${ }^{1}$. The South African census reported that $38 \%$ of Cape Town residents have PCs at home [41]. Another study found PCs in 34\% of homes in Cape Town and 38\% of homes in Johannesburg [42]. Additionally, 86\% reported access via phone, at least once in the past. As expected, teens were more likely to report accessing the Internet via school PCs and less likely to report access via work PCs. More adults than teens reported visiting cybercafés. In terms of activities, browsing/searching was the number one activity, with over $80 \%$ of both teens and adults planning to do so that day. About $40 \%$ of teens and adults planned to seek help on the Internet while at the PAV.

Additional analysis revealed that $90 \%$ of teens and $95 \%$ of adults reported owning a cell phone. More interesting is that $82 \%$ of adults reported bringing their phone to the PAV while only $56 \%$ of teens did so. The significant difference $(x 2 \mathrm{p}<.001)$ is probably due to school regulations, which prohibit students from having and using cell phones during the day because of concerns about safety and theft.

The phase two interviews provided additional insight into the interplay of platforms, venues, and uses. Google search (98\%) and word processors (92\%) were used by most teens: the mobile chat program MXit was popular $(88 \%)$ while the more recently adopted social network Facebook was also used by many teens in this group $(69 \%)$.

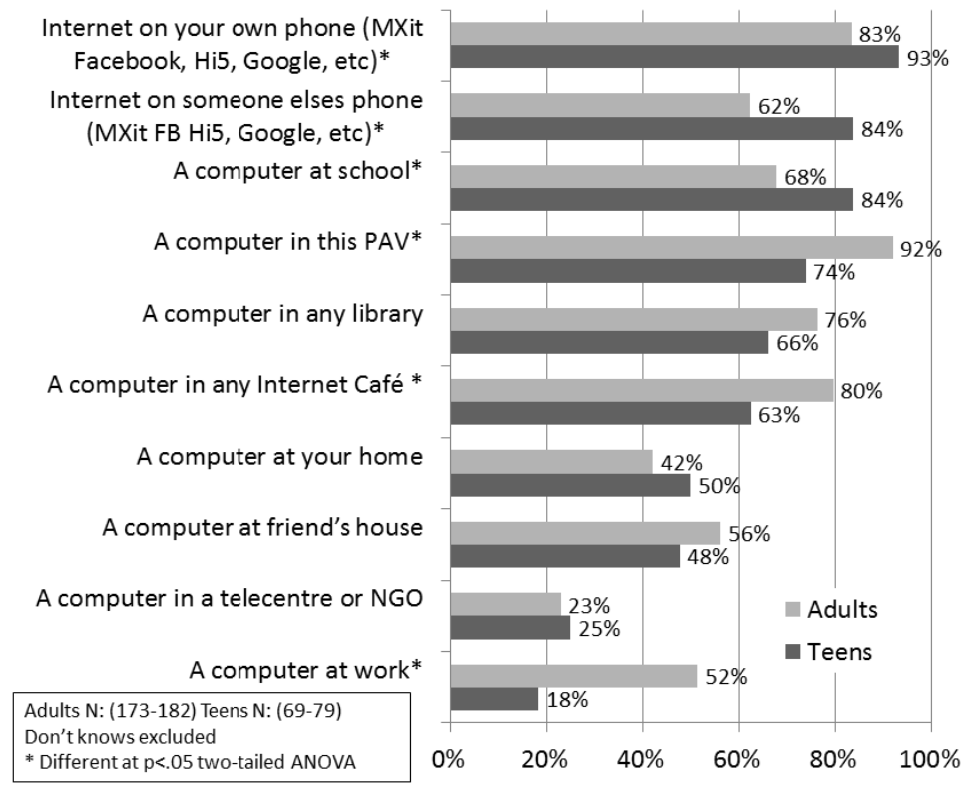

Fig. 1. Phase III Survey "Before today, where else have you accessed the internet?"

\footnotetext{
${ }^{1}$ PC ownership does not imply home internet access; according to the 2011 census [41] around $18-19 \%$ of urban PC owners report no home internet access.
} 
Some tasks were clustered to take advantage of the functions and affordances of a specific platform (PC or mobile). No one used word processors on their phones. Similarly, no one preferred to use MXit on a computer. The inability to multitask on, print from, download, or display large images on a mobile phone were seen as disadvantages, and writing down information from a mobile screen was viewed as a highly inconvenient way of transferring information.

Hybrid or cross-platform practices characterized the use of Google Search and Facebook. PCs were the preferred platform for Google search, with users able to transfer their skills to mobile. Cross-platform use seemed to be the preferred way of using Facebook, with participants electing to use the accessibility and privacy of mobiles together with the convenience and economy of computers. This allowed them a less expensive mode of access, better ergonomics as well as an expanded set of features, particularly instant messaging (not available on mobile Facebook at the time).

Costs were a persistent factor. L explains: "Sometimes I don't have money to go to the Internet cafe and don't have money to use my sister's phone, so I do come here", and A. concurs: "I use a computer when I do not have airtime and I use cell phone when I have airtime". Phones were a way of accessing the mobile web 'ka ncinci', just a tiny bit - costly but cheaper than hourly fees in an Internet cafés.

Many web pages download painfully slowly on phones. Some networks bill for data by time rather than by megabyte, and our observations of mobile internet use showed that young people avoided certain actions on the mobile web to avoid costly downloads.

Time constraints were also a factor in free PAVs, where restrictions on PC use times as short as fifteen minutes prompted quick-turnaround 'match and grab' searchcopy-paste-print routines adapted to the pressurized library environment. In other cases, longer periods at the computer (as in the internet cafés) or regular visits to the library allowed more sustained involvement in editing and visual design as well as integration with handwritten and photocopied material.

Those with airtime and data resources took delight in contacting peers on Facebook via mobiles. MXit allowed a more economical, less interrupted mode of interaction:

\section{- N: If I don't have airtime, I have like one Rand, I go on MXit, chat with my friend the whole night. (f 15)}

Since MXit costs were so low, interactions proliferated, shifting freely into popular games. The low costs of MXit also allowed evasion of parental surveillance and regulation. This freedom and abundance of communication allowed for a multitude of interactions via MXit, which we did not observe with the more expensive channels.

Some interviewees framed their interactions on MXit as a separate space, cut off from institutional ecologies. They were adamant that their use of MXit, games, or other mobile applications was entirely for pleasure, and bore absolutely no relation to schoolwork or other institutionally approved 'instrumental' uses. While the mobile internet was well established in the informational ecosystem, both project network diagrams in Phase II interviews and the Phase III survey indicated that it was not often utilized for schoolwork. 


\subsection{The PAV Ecology Supports a Valued and Non-substitutable Repertoire of Practices for Resource-Constrained Users, Even Those with 'the Internet in Their Pocket'}

Clearly, phones support elements like social networking, media sharing (SD cards, photo sharing, and music playback) [43] and chat through teens' friendship-based ecologies and peer practices. Do teens still require PAVs? We highlight three assertions in the affirmative below.

First, we asked PAV operators: "In your community, has it made a big difference to have public access to the internet in your venue?" Overall, 33 of 36 respondents answered yes. The most common theme, mentioned by 15 respondents, was the way the PAV helped people search for employment. Other responses, less common, included confidence (11 mentions) and the provisioning of a safe space ( 7 mentions). As predicted [44], the biggest difference between free and paid venues was in the issue of cost: 10 of 25 of the free venues mentioned their primary effect in terms of the subsidy of free access. Contrast these quotes from venue operators:

- Cybercafé: We have very good parking facilities and are located in a mall, so people feel very safe to come here, or to drop their children off here

- Library: It's free of charge. And it's a central safe place. Sometimes if we're offline, people will go look for other libraries. It's helped so much for development. People can keep an eye on tenders, or look for jobs online, create CVs - at no cost.

- Library: For school children it helps to get the most recent information we cannot provide with books. That makes their life more easy. And also from our side, information is not on books yet. So we go onto the internet...

PAV operators were asked if there were other options for getting internet in their communities. Generally, the libraries mentioned the cybercafés and vice-versa. The differentiator is price. Consider these responses:

- Cybercafé: The library is around the corner, where people have free internet for 45 minutes. We often get the people who do not have patience to wait at the library. Even though they have to pay, the rates are good and they would rather pay than have to wait...in a queue.

- Library: People come to the library cause the internet is free, even phones are too expensive. We've even had clients saying that they do have internet at home, but they prefer to work at the library cause they don't have to pay for the data

Overall, cybercafés framed their effect as transactional based on convenience and access. Libraries stressed transformational elements of confidence and training, but also the financial subsidy.

Second, in 39 of the 53 Phase II interviews, we asked teens why they were in the PAV that day. The majority $(69 \%)$ of respondents in this group had come to the venue for reasons, which they presented as primarily serious, such as working on a school project or studying. Two had come to assist a younger sibling with schoolwork, and three had come for other reasons (sending faxes for a parent's business, attending 
a training course, or creating publicity posters for a non-profit concert to raise funds). Many had come to the venue with more than one purpose, one related to schoolwork and another related to socializing, either online (18\%) or at the venue $(5 \%)$, or pursuing an interest or hobby.

The South African school curriculum envisages an ecology, which simply does not exist, requiring project-based learning despite the limited availability of resources, such as computers, books, and libraries in public schools. As a result, both schools and young people rely on public libraries. As A. (age 19, library) explained, she would be 'prevented from learning' if she did not have access to the public library: 'all the schoolwork requires you to get information here at the library'. Public access venues also extended to home ecologies, which often did not provide computers or appropriate spaces for homework.

Several participants claimed that the availability of the libraries and internet cafes had helped them achieve higher grades at school. For example, M (m, 17) attributed success of passing the school year to web searches: 'one can say [Google] helped me pass!'

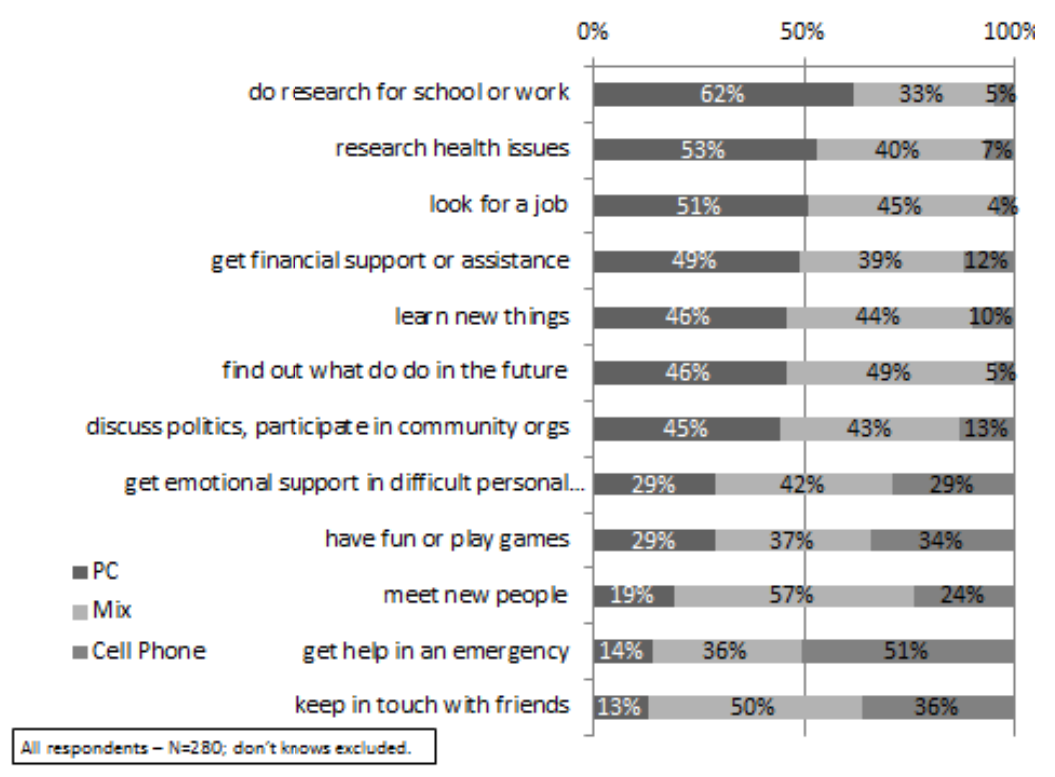

Fig. 2. Phase III Survey Stated Preferences for Tasks

Interviewees had a number of theories about what had helped increase their grades, including whether the venue had helped them to find and edit information, improved their visual presentation and neatness, and assisted them in meeting tight deadlines. They mentioned both the convenience of digital writing and the dividends paid when a 'neat' and 'professional' appearance of their projects translated into higher grades. 
Third, we asked survey respondents whether they preferred to complete a series of tasks exclusively on the PC in the PAV, exclusively on their mobile, or using a mix of the two devices (for parsimony, we were unable to separate out mobile internet from the mobile in general). There were no significant differences between the preferences of teen vs. adults, although the results showed plenty of variance amongst the tasks. There are two key patterns here. First, participants preferred completing instrumental items (research, health, job search, learning new things) on PC only than on mobileonly. Second, the most common answers were often "a mix" of PC and phone - respondents did not want to choose between the devices. This is evidence for emerging complementary rather than competitive roles of PCs and phones.

Taking away the "mix" option, we asked: "if you had to choose between using only your phone for a month or only the computer in the center, which would you pick?" Teens were slightly more likely than adults to say the phone (61\% vs. $52 \%)$, although the difference was not statistically significant. We also asked "if Internet access was free on your cell phone network, would you still use the PAV?" Overall, 54\% of teens and $63 \%$ of adults said they still would, although again the difference was not significant.

\subsection{Teens Can Use a Combination of Mobile and Public Access Internet Resources to Participate in Media Production}

Some examples from studies on social support and media production illustrate different ways in which fixed and mobile internet are complementary, and hint at ways PAVs could be more welcoming of the mobile internet. Almost all of the interviewees used MXit as an academic backchannel to update one another about schoolwork or to assist one another with homework and projects. For example, A (f, 18) was able to use MXit to catch up on missed homework ('I would ask my friend through MXit'), or in the case of an accounting project, to co-ordinate. Mobile phones are powerful enablers of photography and audio and video recording, but publishing and downloading audio-visual media via mobile networks is expensive and can be slow, thus phones were used for media production and (to a lesser extent) editing media, while computers and PAVs were used to produce CDs and DVDs or browse visually intensive sites. One member of a singing group used a computer to produce a CD of their songs, while another participant used the library to administer an amateur drama group and Facebook to sell a DVD of their production. These examples reveal how bandwidth and airtime constraints limit networked sharing of audio and video.

Most of the networked media production we encountered involved simple photo editing on feature phones, L. (f, 16) explained that she had edited her Facebook profile image using software on her feature phone, annotating it with the following message using a green typeface $[e e . . .]^{*}$ Hahahaah ... preettyy ...* . The distinctive orthography, imitation of speech, and use of symbols suggest that such images are an extension of her mobile messaging practices. For her, annotated and tinted shots held a certain distinction: A picture is just a boring picture. Everything must be edited, it looks so stylish..... 


\subsection{PAV Operator Policies Strongly Affect the Chances for Simultaneous, Complementary Use of the Mobile Internet in the Venue}

Phase one discovered differences between cybercafés and free venues in mobile internet use. Among the 11 cybercafés, 8 said that users printed files from their phones, and 8 had seen other examples of 'simultaneous use' of mobiles and PCs. Among the free venues, these observations were less frequent. Ten out of 25 reported that phone users printed files from their phones. Twelve out of 25 had seen instances of simultaneous use.

Some of this gap was likely due to differences in clientele, with older, more affluent users visiting the cybercafés. Beyond this, different venues offered different services and enforced different rules. Contrast these operator responses:

- Cybercafé: We help with everything. Whatever question. We don't mind. If it has anything to do with internet. On the phone or on the computer. We help. That is our service.

- Cybercafé: Sometimes people ask how to set up email on the phone. We help them, but charge for it. 15 min help $=10$ Rand.

- Library: The system always gives us problems with USB connection, when they use the phone on the computers. No one was allowed to log in. We had to shut down the server and then switch on again.

- Library: When we see them on MXit or Facebook we are lenient. But we tell them that it is very dangerous to have the phone with them.

Thus a venue's rules and policies are a major influence on complementary, simultaneous use of mobile internet and PAVs. Nine of the eleven cybercafés had no rules about cell phone use. By contrast, six of the libraries had total bans, eight said phones should be silent, and another four specified phones should not be connected to PCs. Five cybercafé operators reported having helped users register for phone-based services or configure their phone; four specifically allowed users to upload photos. Four free venues blocked USB ports for phone uploads/downloads. Only three helped configure phones, and another three said their users knew more than they did about phones. Cybercafés charged the equivalent of a dollar or two to help a user set up a phone, and they were more than happy to allow uploads and downloads from the phone.

\section{Discussion}

The discussion builds on these findings by questioning the declaration of a closed "digital divide" and identifying steps designers, policymakers, and venues can make to allow PAVs to be more effective in the coming age of mobile internet.

Though we are not the first to critique oversimplifications of how mobile internet promises to 'close the digital divide' [45], our work shows the continuing importance of safe, well-equipped venues such as these. Computers in particular play a key role in ecologies of resource-constrained feature phone users. Young people who could, 
in theory, be "mobile-only" internet users have instead constructed a "mobile-centric" repertoire, relying on the PAV to complete certain tasks required by school and work as well as to save money. Mobiles played a central role in participation in networkbased peer interactions but the PAV was central to other kinds of participation. Public access continues to offer (at this time and in this population) critical value in certain activities. Mobile internet is making great strides, but does not yet substitute for public access, considering hardware, network, cost, space, printing, and guidance. Following [46], public access via the PC and private mobile access may be different enough to complement rather than substitute each other. Our findings echo those of [47] in the context of higher education, suggesting that while phones are used extensively in educational contexts, computer users enjoy a wider range of choices and greater convenience.

\subsection{Policy and Design Changes}

Phase III respondents rated their interest in PAVs' mobile phone allowances (Figure 3). There was relatively more interest in allowing Wi-Fi connections, printing directly from phones, and booking places at PCs by SMS or phone than in rule changes or booths to allow voice. Our results suggest changes in policies and design in five domains, detailed below. Our Phase IV consultations with the PAV stakeholders influenced discussion and interpretation of these results. The design and policy recommendations are intended to inform not only in the South African context, but also for public access points in other resource-constrained settings where users are increasingly likely to have dataenabled phones.

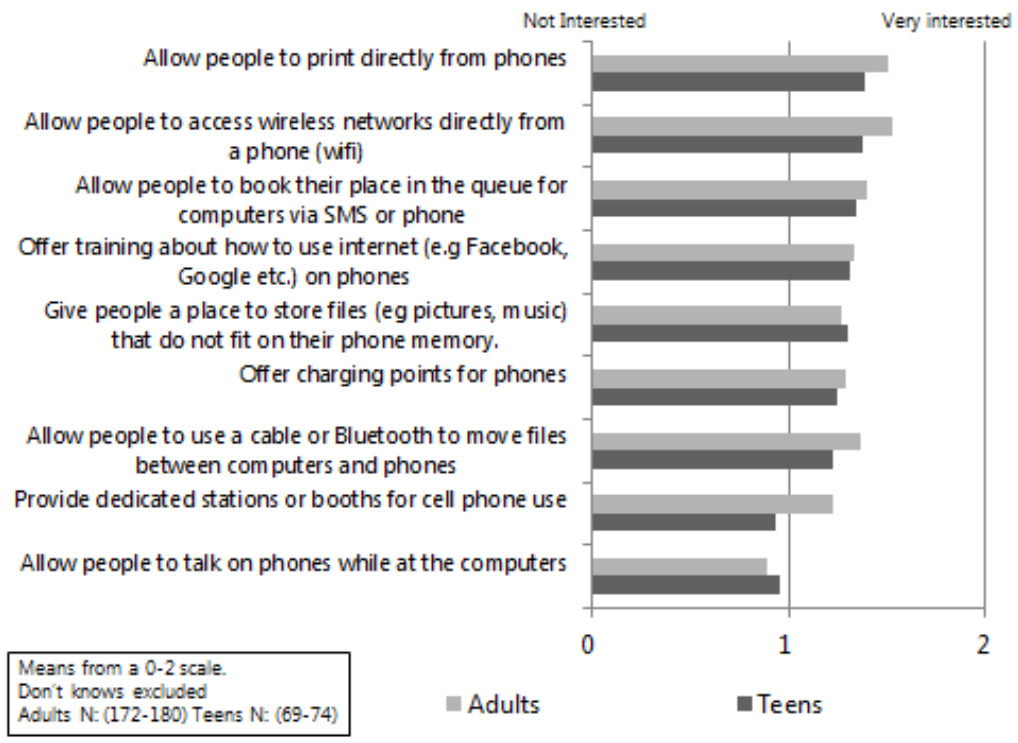

Fig. 3. Actions PAVs Could Take to Improve Phone Use 
Rules. At a basic level, the "rules" prohibiting cell phone use in libraries are simply about noise management, but blanket bans could be replaced with rules to limit noise. All of the phase IV consultees were amenable to this rule change.

Affordances. If connected in some way, phones could be better storage devices, increasing the coherency of short PAV sessions and cutting down on costly intersession printing. Since viruses are a major concern and a drag on scarce support resources [48], phase-IV consultees preferred web-based and wireless solutions to physical connections. With the assistance of design, PAVs could support the more cost-effective methods of transferring text or images to mobile-friendly cloud-based storage, and free transfer to phones via Bluetooth or USB cable.

Equally important, designs allowing phones to interface better with paper in school ecologies might include mobile interfaces for PC-less printing or mini design apps for creating printable display text or diagrams on feature phones. Phone cameras or scanning apps could help shorten queues for copiers.

Skills. Librarians and other PAV operators outside of those in for-profit cybercafés may benefit from specific training and encouragement oriented towards the opportunities presented by the mobile internet. With the proper skills, PAV staff could help users save time waiting for shared resources and encourage them to get more out of the internet in their pocket. PAV operators need new skills to help mobile-centric users with things like configuring email on phones to searching, cloud storage, and local caching, and less technical (but critical) skills, such as managing time, contacts, online reputation, and use of mobile-accessible resources for leisure and school. In Phase IV, we discussed the development of posters, covering topics such as cloudbased storage and photo processing, which might augment and backstop training provided to PAV staff. Individual tips could also be saved as small graphics and distributed via Bluetooth.

Framing. These shifts in rules and skills are not simply a matter of technical changes. Our interviews highlighted the suspicion with which PAV operators (particularly librarians) viewed phones, emphasizing negative associations with time wasting, dangerous social networks, destructive viruses, and the like. Many missed the remarkable potential that some teens had identified - the value of linking their personal digital devices to a shared access resource. Phase IV participants suggested that libraries could curate and promote electronic sources designed specifically for mobile platforms to encourage people to explore to identify and take advantage of what their phones can do as a complement to PC internet access. Free public access venues can (continue to) support young people's mobile-centric activities beyond schoolwork, such as games, media production and distribution, and social networking, thus reframing PAVs to support participation in youth culture beyond the dominant ecologies of schooling.

Some librarians would be opposed to teens using media in the libraries, particularly noisy gaming; thus, they may oppose groups of young gamers were likely to disturb 
other patrons. "We do allow games but the librarian has the right to say that if they are too rowdy they must quiet down or cut the sessions". Another problem relates to the fact that parents might be using the libraries as a 'babysitting' facility. Although librarians object to becoming afterschool supervisors, there is recognition that kids have few other places to go, and at least the library is a safe place. Hence, it is important to make the PAV an interesting and enjoyable place for kids pursuing various goals. Other PAVs in settings where security is less of an issue or where there are more alternatives may select different policies in this case.

Bits. Part of the appeal of the public PAVs remains free (subsidized) bits. In a country where internet data remains expensive, the long lines for PC access are understandable. On the one hand, this is a key observation regarding mobile design for resourceconstrained settings. The free community hotspots common in more prosperous contexts [49] remain rare in places where bits are relatively expensive. The Wi-Fi feature of a handset is of little use to those who cannot afford to turn it on.

A more complementary policy view of Wi-Fi-enabled handsets could reduce pressure on library PCs to provide enough time for everyone. Phase IV consultees described how two of the central libraries had instituted Wi-Fi options. However, they were adamant that provisions needed to be in place to refund PAV's for the cost of their bandwidth.

Nevertheless, disaggregating the access to the machine from subsidy of the bits and increasing the flexibility, utility, and accessibility of both could be an effective move. One study suggested that worldwide, $50 \%$ of mobile phone users access the internet via Wi-Fi rather than the cell network [50]. With the spread of lower-cost dataenabled handsets, resource constrained people (without access to $\mathrm{Wi}-\mathrm{Fi}$ at home, school, or work) would like free hotspots, too.

In summary, there is an opportunity for public PAVs to not simply follow the lead of cybercafés, but rather to go further in supporting their users' increasingly mobilecentric internet behaviors. Through a combination of staff training, updated rules, a Wi-Fi connection (cost permitting), and perhaps some cabling and charging stations, PAVs could provide valuable mobile-related services to users with a relatively modest investment in materials and time. Design could support specific shared-PC and ownmobile scenarios around printing, file management, and storage. Even PAV owners and frontline staff with low-resources could begin to treat the mobile internet less as an affliction (social networking) or threat (substitution) and more like the supplement to PC Internet access, as suggested by our analysis and interviews suggest it can be.

\subsection{Limitations and Next Steps}

The methodological limitations of a non-representative sample were discussed in the methods section. Here, we reflect on broader issues of generalizability. On the one hand, the purposive sample was appropriate for this research topic at this time. Young people in urban townships in this area are a leading case vis-à-vis mobile internet use, 
and the patterns we identify here will become prominent as more adopt data-enabled phones emerge in South Africa and elsewhere on the continent. Relatively good public facilities in Cape Town suggest possibilities of public access for state, schools, and businesses alike. Lower levels of PC use or of mobile internet adoption would not have allowed us to explore demand for coexistent, complementary, or competitive uses with any certainty. On the other hand, the uses observed in 2011 are a "snapshot" of an ongoing process. Conditions are changing as more mobiles become more internet-enabled, as smart phones and tablets become more affordable, as schools invest in ICTs, and as bandwidth tariffs come down. The progression towards lower cost and 'converged' devices may over time erode the current stark differences in affordances between public PCs and private mobiles. Thus, we are reluctant to make forecasts regarding how long the conditions (and repertoires) we observed will persist or to how long it might be before teens, as the ones we met will be able to do without public access internet. This is likely to happen before they will stop needing safe public spaces, which are conducive to learning, social networking, and cultural participation. Instead, we hew closer to current conditions to suggest some immediate steps that policymakers and PAV operators can take.

Space constraints in the paper have prevented us from addressing how broader patters of social and economic constraints shape participation and available ecologies, but this will be addressed elsewhere in a later publication. In brief, South African inequalities show how starkly power and economic stratification shape ecologies and user repertoires. Simultaneously, school and work shape demand, requiring and rewarding the genres that index middle-class ecologies.

\section{Conclusion}

Ecological metaphors encourage us to see PAVs as places of agency, which support learning, growth, and adaptation. Nonetheless, PAVs also interface with broader markets of participation and access. Those who can pay enjoy relative freedom to communicate, while those who cannot, must conform to rules designed to serve institutional ecologies and the adult 'owners' of PAV spaces, who often, particularly in the case of free public services, stigmatize, misrecognize, and fail to support young people's mobile repertoires.

The snapshot we offer is one of stark practical and conceptual splits between (public) PCs and (private) mobiles. We see little evidence in this context that demand for PAVs among resource constrained, mobile internet-using teens will decline in the near-term, but also identify opportunities associated with the increasing prevalence of data-enabled handsets among PAV users. Thus, we suggest improvements in rules, changing affordances, upgraded skills, revised framing, and a different provision of bits (Wi-Fi) in order to help "welcome the mobile internet into the public venue".

These steps require support and funding from policymakers, and they are also a fruitful ground for interaction designers and technologists. All can be undertaken immediately to help this generation of teens, rather than waiting for convergence or lower mobile tariffs to help the next one. 
Acknowledgements. This research was part of the Global Impact Study of Public Access to Information \& Communication Technologies (globalimpactstudy.org) implemented by the University of Washington's Technology \& Social Change Group with support from the International Development Research Centre (IDRC) and a grant from the Bill \& Melinda Gates Foundation. We are also grateful for the contributions of the project team members, Silke Hassreiter, Anja Venter, Minah Radebe, Muya Koloko, Nombuyiselo Dziba, Juliette Manitshana, Baxolele Zono and Thabisa Xhalisa. Furthermore, we thank Amaal Davids and the support of Library and Information Services, City of Cape Town, Cape Access (Provincial Gov. of the Western Cape), African Axess and Silulo Internet Cafés, and the participants, without whom the research would not have been possible.

\section{References}

1. Morgan Stanley Research: The Mobile Internet Report: Ramping Faster Than Desktop Internet, the Mobile Internet Will Be Bigger Than Most Think. Morgan Stanley \& Co., New York (2009)

2. Ajao, O.: Are Mobile Phones Pushing Cyber Cafes Out of Business? (2010), http: / / www. ictworks . org/news / 2010/05/10/ are-mobile-phones-pushing-cybercafes-out-business

3. Samii, R.: Mobile Phones: The Silver Bullet to Bridge the Digital Divide? Participatory Learning and Action 59, 44-50 (2009)

4. Chigona, W., Lekwane, O., Westcott, K., Chigona, A.: Uses, Benefits and Challenges of Public Access Points in the Face of Growth of Mobile Technology. The Electronic Journal of Information Systems in Developing Countries 49, 1-14 (2011)

5. McEwen, R., Scheaffer, K.: Orality in the Library: How Mobile Phones Challenge Our Understandings of Collaboration in Hybridized Information Centers. Library \& Information Science Research 34, 92-98 (2012)

6. Prasad, R.: Rupamanjari Sinha Ray: Telecentres Go Where Mobile Phones Fear to Tread: Evidence from India. In: Regional International Telecommunications Society India Conference, New Delhi, pp. 1-26 (2012)

7. Licoppe, C.: "Connected" Presence: The Emergence of a New Repertoire for Managing Social Relationships in a Changing Communication Technoscape. Environment and Planning D 22, 135-156 (2004)

8. Nardi, B., O'Day, V.: Information Ecologies: Using Technology with Heart. MIT Press, Cambridge (1999)

9. Walton, M., Donner, J.: Public Access, Private Phone: The Interplay of Shared Access and the Mobile Internet for Teenagers in Cape Town (Global Impact Study Research Report Series), Cape Town (2012)

10. Higgs, N.T.: Measuring and Understanding the Well-being of South Africans: Everyday Quality of Life in South Africa. Social Indicators Research 81, 331-356 (2006)

11. Skuse, A., Cousins, T.: Getting Connected: The Social Dynamics of Urban Telecommunications Access and Use in Khayelitsha, Cape Town. New Media \& Society 10, 9-26 (2008)

12. Skuse, A., Cousins, T.: Managing Distance: Rural Poverty and the Promise of Communication in Post-apartheid South Africa. Journal of Asian and African Studies 42, 185-207 (2007) 
13. Oyedemi, T.D.: Social Inequalities and the South African ICT Access Policy Agendas. International Journal of Communication 3, 151-168 (2009)

14. Chetty, M., Banks, R., Brush, A.J.B., Donner, J., Grinter, R.E.: While the Meter Is Running: Computing in a Capped World. Interactions 18, 72-75 (2011)

15. Sey, A., Fellows, M.: Loose Strands: Searching for Evidence of Public Access ICT Impact on Development. In: Proc. iConference 2011, pp. 189-194. ACM, New York (2011)

16. James, T., Finlay, A., Jensen, M., Neville, M., Pillay, R.: Public Access ICT in South Africa. In: Gomez, R. (ed.) Libraries, Telecentres, Cybercafes and Public Access to ICT, pp. 429-451. IGI Global, Hershey (2011)

17. Pather, S., Gomez, R.: Public Access ICT: A South-South Comparative Analysis of Libraries, Telecentres and Cybercafés in South Africa and Brazil. In: AMCIS 2010, Lima, pp. 1-11 (2010)

18. ITU: Mobile-cellular Subscriptions Per 100 Inhabitants (2001-2011), http://www . itu.int/ITU-D/ict/statistics/material/excel/2011/Mobile_ cellular_01-11.xls

19. World Wide Worx: Mobility 2011: The Mobile Internet in South Africa 2011 (executive Summary), Johannesburg (2011)

20. Bosch, T.: Wots Ur ASLR? Adolescent Girls' Use of Cellphones in Cape Town. Commonwealth Youth and Development 6 (2008)

21. Chigona, A., Chigona, W.: MXit up in the Media: Media Discourse Analysis on a Mobile Instant Messaging System. The Southern African Journal of Information and Communication 9, 42-57 (2009)

22. Schoon, A.: Raw Phones: The Domestication of Mobile Phones Amongst Young Adults in Hooggenoeg (2012), http: / / eprints.ru.ac. za/2894/

23. Walton, M., Donner, J.: Read-Write-Erase: Mobile-mediated Publics in South Africa's 2009 Elections. In: Katz, J.E. (ed.) Mobile Communication: Dimensions of Social Policy, pp. 117-132. Transaction Publishers, New Brunswick (2011)

24. Walton, M., Pallitt, N.: "Grand Theft South Africa": Games, Literacy and Inequality in Consumer Childhoods. Language and Education 26, 347-361 (2012)

25. Gitau, S., Marsden, G., Donner, J.: After Access - Challenges Facing Mobile-only Internet Users in the Developing World. In: Proc. CHI 2010, pp. 2603-2606. ACM, New York (2010)

26. Brown, C., Czerniewicz, L.: Debunking the "Digital Native": Beyond Digital Apartheid, Towards Digital Democracy. Journal of Computer Assisted Learning 26, 357-369 (2010)

27. Chigona, W., Beukes, D., Vally, J., Tanner, M.: Can Mobile Internet Help Alleviate Social Exclusion in Developing Countries? The Electronic Journal of Information Systems in Developing Countries 36, 1-16 (2009)

28. Kreutzer, T.: Generation Mobile: Online and Digital Media Usage on Mobile Phones Among Low-income Urban Youth in South Africa (2009), http://www.tinok reutzer.org/mobile/MobileonlineMedia-SurveyResults-2009.pdf

29. Bloch, G.: The Toxic Mix: What's Wrong with South Africa's Schools and How to Fix It. Tafelberg, Cape Town (2009)

30. Fleisch, B.: Primary Education in Crisis: Why South African Schoolchildren Underachieve in Reading and Mathematics. Juta and Company (2008)

31. Statistics South Africa: Quarterly Labour Force Survey: Quarter 3 (July to September), Pretoria (2011)

32. Donner, J.: Research Approaches to Mobile Use in the Developing World: A Review of the Literature. The Information Society 24, 140-159 (2008) 
33. Goldstuck, A.: The Mobile Internet Pinned Down, http://www.worldwideworx. $\mathrm{com} /$ the-mobile-internet-pinned-down/

34. Wyche, S.P., Smyth, T.N., Chetty, M., Aoki, P.M., Grinter, R.E.: Deliberate Interactions: Characterizing Technology Use in Nairobi, Kenya. In: Proc CHI 2010, pp. 2593-2602. ACM, Atlanta (2010)

35. Wang, T., Brown, B.: Ethnography of the Telephone: Changing Uses of Communication Technology in Village Life. In: Proc Mobile HCI 2011, pp. 1-10 (2011)

36. Foth, M., Hearn, G.: Networked Individualism of Urban Residents: Discovering the Communicative Ecology in Inner-city Apartment Buildings. Information, Communication \& Society 10, 749-772 (2007)

37. Chiumbu, S.: Exploring Mobile Phone Practices in Social Movements in South Africa the Western Cape Anti-Eviction Campaign. African Identities 10, 193-206 (2012)

38. Lindtner, S., Nardi, B.A., Wang, Y., Mainwaring, S., Jing, H., Liang, W.: A Hybrid Cultural Ecology: World of Warcraft in China. In: Proc. CSCW 2008, p. 371. ACM Press, New York (2008)

39. Pearson, M., Somekh, B.: Concept-mapping as a Research Tool: A Study of Primary Children's Representations of Information and Communication Technologies (ICT). Education and Information Technologies 8, 5-22 (2003)

40. Mavers, D.: Interpreting the Externalised Images of Pupils' Conceptions of ICT: Methods for the Analysis of Concept Maps. Computers \& Education 38, 187-207 (2002)

41. StatsSA: Community Profiles (SuperWeb Interactive Format) (2012)

42. SAARF: All Media Products Survey (2012)

43. Walton, M., Marsden, G., Hassreiter, S., Allen, S.: Degrees of Sharing: Proximate Media Sharing and Messaging by Young People in Khayelitsha. In: Proc. MobileHCI 2012. ACM Press, New York (2012)

44. Gomez, R., Pather, S., Dosono, B.: Public Access Computing in South Africa: Old Lessons and New Challenges. Electronic Journal of Information Systems in Developing Countries 52 (2012)

45. Gurumurthy, A.: From Social Enterprises to Mobiles - Seeking a Peg to Hang a Premeditated ICTD Theory in an Ecology of Unequal Actors. Information Technologies \& International Development 6, 57-63 (2010)

46. Bar, F., Best, M.L.: Assessing the Impact of Public Access to ICTs. Information Technologies and International Development 4 (2008)

47. Czerniewicz, L., Brown, C.: Born into the Digital Age in the South of Africa: The Reconfiguration of the "digital Citizen". In: Proc. Networked Learning 2010, pp. 859-865. Lancaster University, Lancaster (2010)

48. Bhattacharya, P., Thies, W.: Computer Viruses in Urban Indian Telecenters: Characterizing an Unsolved Problem. In: Proc ACM Workshop on Networked Systems for Developing Regions (NSDR 2011), pp. 1-6. ACM, New York (2011)

49. Forlano, L.: Anytime? Anywhere?: Reframing Debates Around Municipal Wireless Networking. The Journal of Community Informatics 4 (2008)

50. Daly, V.: Wi-Fi Grows to over $50 \%$ of Mobile Web Connections, http: //news . bango.com/2011/02/02/wi-fi-grows-to-over-50percent/ 